\title{
Changes Caused by the Melatonergic System in Young Patients with Mood Disorders: A Literature Review
}

\author{
Jung Hyun Lee, MD, PhD', Eunsoo Moon, MD, PhD ${ }^{2,3}$ \\ ${ }^{1}$ Department of Pediatrics, Kosin University College of Medicine, ${ }^{2}$ Department of Psychiatry, Biomedical Research Institute, Pusan National \\ University Hospital, Busan, ${ }^{3}$ Department of Psychiatry, Pusan National University School of Medicine, Yangsan, Korea
}

The abnormalities caused by the melatonergic system have been associated with psychiatric disorders, such as Alzheimer's dementia and schizophrenia, as well as with the pathogenesis of mood disorders. Abnormal melatonin secretion has been observed in the early phase of mood disorders in young patients and high-risk adults. This review summarizes and discusses the findings of studies that have investigated the melatonergic system in children, adolescents, and young adults with mood disorders. Furthermore, the factors associated with the changes caused by the melatonergic system during the early stage of mood disorders are evaluated.

Keywords Depression; Bipolar disorder; Melatonin; Child; Adolescent

\section{INTRODUCTION}

The abnormalities of melatonergic system have been observed in several psychiatric disorders. Patients with Alzheimer's dementia showed significantly lower total melatonin secretion and amplitude of melatonin rhythm and larger variation of acrophase than nondemented elder people [1]. Vascular melatonin MT1-receptor significantly increased in hippocaumpus of patients with Alzheimer's dementia compared to human control hippocampus [2]. The increase of vascular MT1-receptor might indicate a regulatory response to impared melatonin secretion [2]. Abnormal melatonergic system in schizophrenia have been also reported [3-5]. Patients with schizophrenia significantly showed lower melatonin levels and more disrupted circadian melatonin rhythm than healthy control $[4,5]$. Recent meta-analysis reported that the volume of pineal gland in schizophrenia significantly decreased compared to healthy control [3]. The decrease of pineal gland volume might lead to impairment of melatonin secretion.
Abnormal melatonin rhythms have been also reported in patients with mood disorders [6,7]. Several studies have found that patients with bipolar disorderare likely to show abnormal melatonin secretion and increased light-induced melatonin suppression [8-11]. In major depression, there were inconsistent findings of melatonin secretion or levels compared to healthy subjects [12-15]. These inconsistent findings could be caused by the variability in the diagnosis of mood disorders in children and adolescents [16,17]. However, the nocturnal melatonin secretion was significantly delayed in patients with major depression as compared to healthy subjects [15]. Additionally, the bed time melatonin levels was closely to depressive severity [18]. Given that the results of previous studies, changes of melatonin systems might be greatly related to mood disorders.

A hypothesis that abnormalities in melatonin system may be linked to the pathogenesis of mood disorders needs to be considered $[6,19]$. If the abnormalities of melatonergic system were associated with the pathogenesis of mood disorder, these abnormalities could be

Received September 29, 2020, Revised November 12, 2020, Accepted November 12, 2020

Correspondence: Eunsoo Moon, MD, PhD

Department of Psychiatry, Pusan National University Hospital, 179 Gudeok-ro, Seo-gu, Busan 49241, Korea

TEL +82-51-240-7303 FAX +82-51-248-3648 E-mail esmun@hanmail.net ORCID https://orcid.org/0000-0002-8863-3413

Copyright $@$ by Korean Society for Affective Disorders. All Rights reserved.

This is an Open Access article distributed under the terms of the Creative Commons Attribution Non-Commercial License (http://creativecommons.org/licenses/ by-nc/4.0/) which permits unrestricted non-commercial use, distribution, and reproduction in any medium, provided the original work is properly cited. 
observed in early phase of mood disorder. Melatonin gradually increases its secretion as it ages [20]. The secretion of melatonin peaks before puberty, and gradually decreases after puberty [20]. Therefore, melatonin secretions vary depending on the time period, it is necessary to analyze melatonin secretions separately during periods such as child, adolescent, and young adults. Moreover, abnormal melatonin secretion might be observed in high risk group for mood disorders. This review aimed to summarize and discuss recent studies on the changes of melatonin rhythm and associated factors in child, adolescent, and young adults with mood disorders in order to explore the relationship between the pathegnesis of mood disorder and changes of melatonergic system. In order to find relevant studies on melatonin change in child, adolescent, and young adult, potential articles were searched in PubMed through following searching strategy: (depression[MeSH] OR "depressive disorder"[MeSH] OR “major depression*" [tiab] OR “major depressive disorder*" [tiab] OR depress*[tiab]) AND (child*OR adolesc*OR youth) AND (melatonin[MeSH] OR melatonin*[tiab]). Initially, 256 articles were found. Articles that were irrelevant to this topic and related to animals or cell models were excluded. Ten articles were finally selected and shown in Table 1 [21-26,34-36].

\section{THE CHANGES OF THE MELATONERGIC SYSTEM IN CHILD AND ADOLESCENT PATIENTS WITH MOOD DISORDERS}

Regarding melatonin rhythm in childhood depression, there was one case-control study [21]. The patients were diagnosed as depressive disorders according to Research Diagnostic Criteria and Diagnostic Statistical ManualThird edition (DSM-III). Only male patients were included in this study. The mean age of patients was $10.2 \pm 1.9$ (from 7 to 13 years). Four patients were on prepubertal period with Tanner stage 1. Five patients were on early or midpubertal period from Tanner stage 2 to 3 . The mean age of 10 healthy subjects were $11.7 \pm 2.5$ (from 9 to 15 years). Six subjects were on prepubertal period with Tanner stage 1 and four were on early or midpubertal period from Tanner stage 2 to 3 . The mean plasma melatonin concentrations during 24 hours and nighttime were significantly lower in patients with childhood depression than healthy control subjects. However, the onset time of the nocturnal melatonin surge and melato- nin peak time were similar in both groups. Furthermore, there was no difference of onset time of the sleep/dark period.

Other case-control study examined nocturnal urinary melatonin excretion in prepubertal children with depression [22]. This study included 31 prepubertal male and female children aged 6 to 14 (Tanner stages 1 and 2) diagnosed as major depressive disorder (MDD) according to the Schedule for Afective Disorders and Schizophrenia for School Age Children. There was significant difference between female MDD patients (6/31, 19.4\%) and female healthy subjects $(9 / 15,60.0 \%)$. The mean age of patients was $10.6 \pm 1.5$ (from 8 to 15 years) and the mean age of healthy controls was $10.1 \pm 1.7$ (from 6 to 14 years). Fiften healthy controls were children with very low family loading for depression. This study did not find the difference of urinary 6-hydroxymelatonin sulfate level that is melatonin metabolite reflecting nocturnal melatonin secretion between both groups.

Meanwhile, there was another case-control study including adolescent male and female patients with depression, as well as childhood depression [23]. Twentytwo depressive patients aged 8 to 17 years were compared with 19 healhty controls. Most of patients $(\mathrm{N}=18)$ were diagnosed wih major depression except 1 patient with severe dysthymia and 3 patients with bipolar depression. Percentage of female depressive patients was $66.7 \%(14 / 21)$, and one of female healthy subjects was $42.1 \%(8 / 19)$. The ratio of pubescent adolescents (Tanner stage 3-5) to prepubescent children (Tanner stage 1-2) were about 2:1. In this study, the serum melatonin secretion was significantly higher in pateints with depression than healthy subjects. Sex and stages of pubescence had no significant effect. In post hoc analysis according to the presence of psychotic symptoms, the depressed patients without psychotic symptoms showed significnalty higher melatonin secretion than healthy subjects. In contrast, the pateints with psychotic depression had a trend of lower melatonin secretion than healthy subjects.

\section{THE CHANGES OF THE MELATONERGIC SYSTEM IN ADOLESCENT AND YOUNG ADULT PATIENTS WITH MOOD DISORDERS}

One study examined the melatonin profiles in 44 adolescents and young adults aged 12 to 30 years during 


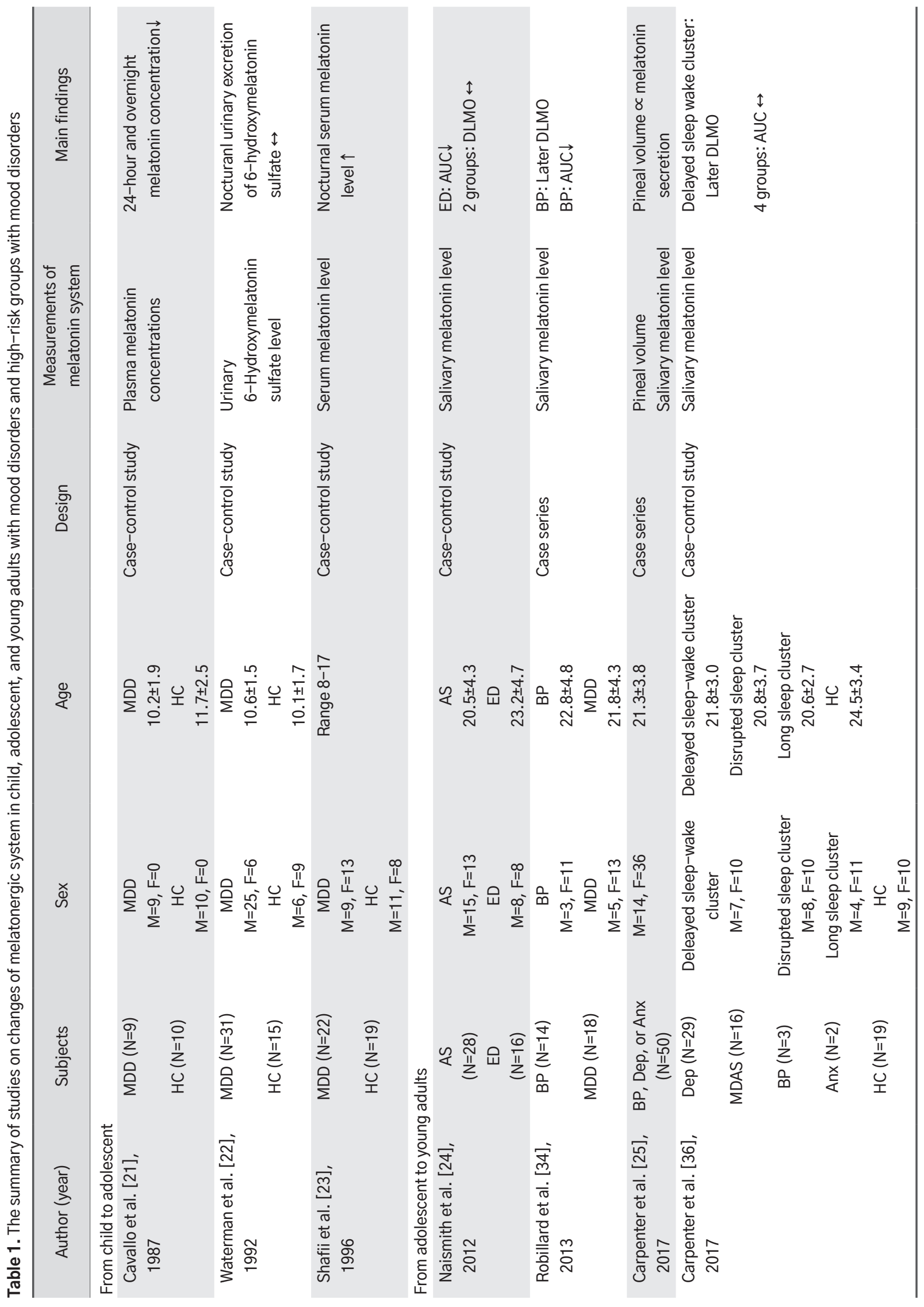




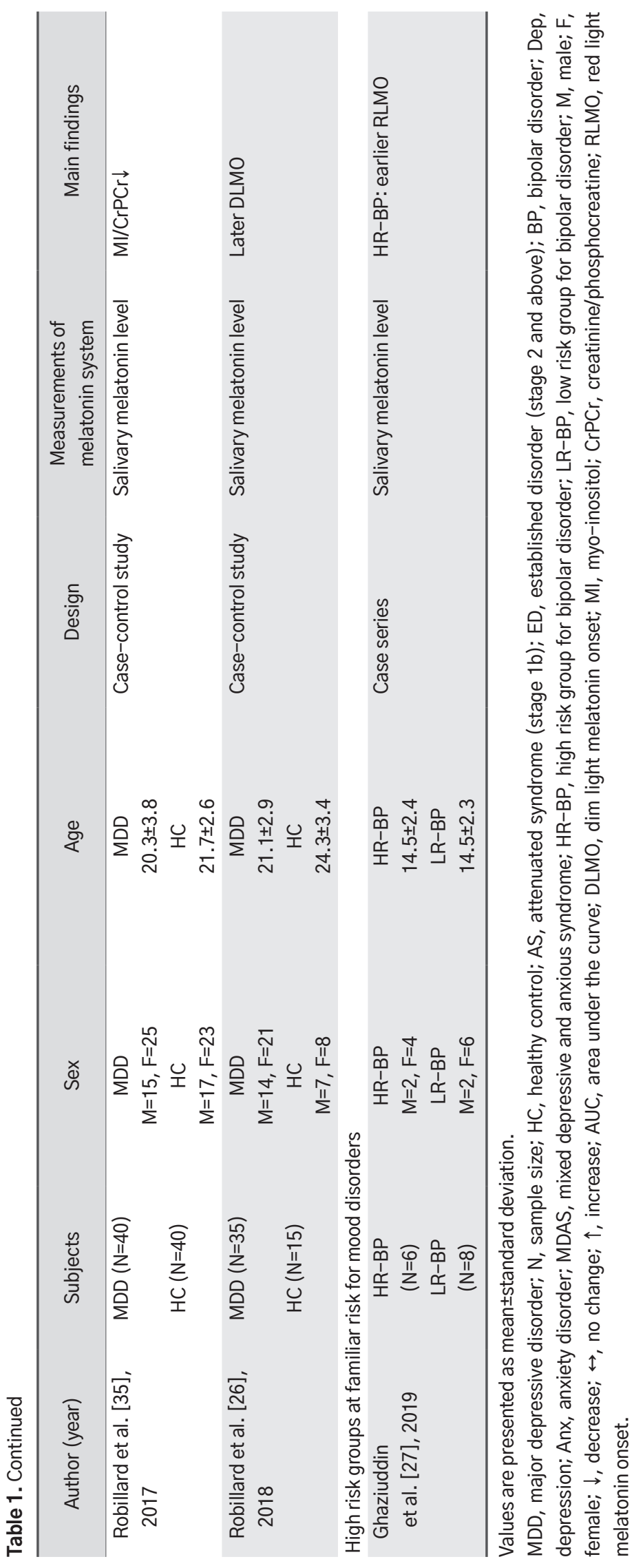


the early stages of affective disorders [24]. This study made patients categorized 'attenuated syndrome' with mild symptoms or an 'established disorder' meeting full-threshold criteria for major depression according to a DSM-IV. The mean age of 'attenuated syndrome' group was 20.5( \pm 4.3$)$ and the mean age of 'established disorder' group was $23.2( \pm 4.7)$. There was no significant difference between female 'attenuated syndrome' group $(13 / 28,46.4 \%)$ and female 'established disorder' group $(8 / 16,50.0 \%)$. There was no significant difference of melatonin onset time between these two groups. However, patients with 'established disorder' had significantly reduced levels of melatonin secretion estimated by area under the curve (AUC) analysis than those with 'attenuated syndrome'

One case-control study compared the sleep-wake profiles and circadian rhythms between adolescent and young adult outpatients with affective disorders and healthy controls [25]. Fifty patients were diagnosed with depressive disorders $(\mathrm{N}=29)$, mixed depressive and anxious syndrome $(\mathrm{N}=16)$, bipolar disorders $(\mathrm{N}=3)$ or primary anxiety disorders $(\mathrm{N}=2)$. By cluster analysis, these pateints were classified into delayed sleep-wake cluster $(\mathrm{N}=17)$, disrupted sleep cluster $(\mathrm{N}=18)$, and long sleep cluster $(\mathrm{N}=15)$. The mean age of each cluster was $21.8( \pm 3.0)$ in delayed sleep-wake cluster, 20.8( \pm 3.7$)$ in disrupted sleep cluster, and 20.6( \pm 2.7$)$ in long sleep cluster respectively. The mean age of 19 healthy controls was $24.5( \pm 3.4)$. The mean age of healthy controls was significantly higher than patients with disrupted sleep cluster or long sleep cluster. There were no significant differences of sex distribution among 3 patients groups and healthy control (female percentage: delayed sleepwake cluster, 10/17 (58.8\%); disrupted sleep cluster, 10/18 (55.6\%); long sleep cluster, 11/15 (73.3\%); healthy controls, $10 / 19(52.6 \%))$. In this study, about $20 \%$ of patients with affective disorders showed low melatonin secretion that did not reach the thresehold for dim-light melatonin onset (DLMO) compared to zero percentage of healthy controls. Patients with delayed sleep-wake cluster significantly showed delayed DLMO compared to healthy controls. The melatonin AUC was calculated using salivary melatonin between 4 hours prior to habitual sleep time until 1.5 hours after habitual sleep time. There were no significant differences of melatonin AUCamong these four groups.

Other case-control study examined circadian rhythms in young adults with major depressive disorder [26].
Thirty-five patients aged 18 to 31 years diagnosed as major depressive disorder $(\mathrm{N}=18)$ or depressive disorder not otherwise specified $(\mathrm{N}=17)$ according to DSM-IV criteria. Fifteen healthy controls were recruited from community. The mean age of healthy controls $(24.3 \pm 3.4)$ was significantly higher than those of patients with depression (21.1 \pm 2.9$)$.There was no significant differencebetween female depressive patients $(21 / 35,60.0 \%)$ and female healthy subjects $(8 / 15,53.3 \%)$. The DLMO of depression group was significantly later than one of healthy control.

\section{THE CHANGES OF THE MELATONERGIC SYSTEM AT RISK WITH MOOD DISORDERS}

One study compared salivary melatonin onset between high risk and low risk gropus in youth at familial risk for bipolar disorder [27]. There was no signficiant difference of age between high risk group (14.5 \pm 2.4$)$ and low risk group (14.5 \pm 2.3 ). Additionally, there was no significant difference of sex ratio between two groups (female percentage: high risk group, 4/6 [66.7\%]; low risk group, $6 / 8$ [75.0\%]). Participants with high risk showed significantly earlier salivary melatonin onset under the condition of red light than those with low risk. Low risk group spent significantly more time in sleep stage 3 and 4 than those with high risk.

\section{DIFFERENCE OF MELATONERGIC SYSTEMS ACCORDING TO SEX AND DIAGNOSTIC SUBYPTES IN MOOD DISORDERS}

Regrading the role of sex on melatonin secretion, female healthy subjects are likely to show higher melatonin secretion than male healthy subjects $[28,29]$. Though the underlying mechanism on preponderance of melatonin secretion in female was unclear, the consistent discrepancy between male and female might be explained by the interaction between melatonin and estrogen when considering the reciprocal existence of melatonin receptors in reproductive organ and estrogen receptors in pineal gland [29-32]. One pausible hypothesis suggests that estrogen might increase melatonin secretion [33]. Meanwhile, there was few comparative results beween 
male and female patientswith mood disorders. Only one case-control study compared the difference of serum melatonin secretion between adolescent male and female patients with depression [23]. However, this study did not find a significant influence of sex on melatonin secretion.

In terms of the effect of diagnostic subtypes on melatonin rhythms, one study compared the sleep-wake cycle and melatonin rhythms between unipolar and bipolar depression [34]. This study included thirty-two patients between 15 and 30 years old. There were no significant differences of age and gender between major depressive disorder $(21.8 \pm 4.3$, female $13 / 18,72.2 \%)$ and bipolar depression $(22.8 \pm 4.8$, female $11 / 14,78.6 \%)$. This study showed that pateints with bipolar disorders had significiantly lower AUC and later onset of melatonin secretion than patients with major depressive disorder. Meanwhile, among major depressive disorder, the presence of psychotic symptoms have a significant influence on melatonin secretion [23]. As previously noted, the depressed patients without psychotic symptoms showed significnalty higher melatonin secretion than healthy subjects. In contrast, the pateints with psychotic depression had a trend of lower melatonin secretion than healthy subjects.

\section{ASSOCIATED FACTORS RELATED TO THE CHANGES OF THE MELATONIN SYSTEM}

Salivary melatonin AUC was not signficiantly associated with severity of depressive symptoms in both 'attenuated syndrome' and 'established disorder' [24], and in young adults with major depressive disorder [35]. Young adult patients in delayed sleep-wake cluster did not show the significant correlation with severity of depressive symptoms measured by HDRS [25]. However, because the classification in this study was performed by using sleep-wake cycle, authors implied that the abnormality of phase angle by using circadian parameters except sleep-wake cycle might be possibly related to depressive symptom severity. Other study with similar designmeasured the phase shifing by using DLMO and core body temperature [26]. In this study, young adults from the delayed cluster with major depressive disorder significantly showed higher HDRS total score than those from conventional circadian timing [26]. Additionally, delayed cluster showed significantly higher Young Mania Rating Scale scores than conventional cluster [26].
Several studies examined the relevance between abnormal melatonin secretion and cognitive, social-occupatonal function. In one study, salivary melatonin AUC was not significantly correlated with cognitive deficits in 'attenuated syndrome' [24]. However, in 'established disorder', lower melatonin levels were significantly correlated with poor verbal memory [24]. Meanwhile, lower melatonin levels and decreased melatonin AUC were significantly associated with poorer social and occupational functioning [36].

In terms of biological features, one observational study examined the volume of pineal gland and melatonin secretion in young people with affective disorders [36]. The mean age of fifty five patients was $21.3 \pm 3.8$ (15-31 years old). The diagnosis of affective disorder included depressive disorder, bipolar disorder, or anxiety disorder according to DSM-IV-TR criteria. Pineal gland volume significantly correlated with maximum melatonin, melatonin AUC. This finding indicate that the pineal gland volume might be one of possible causes on abnormal melatonin secretion. In other study, later DLMO was significantly correlated with lower myo-inositol (MI)/creatinine/phosphocreatine (CrPCR) ratio in young adults with depression [35]. Considering that MI/ CrPCR ratio means myo-inositol levels as a glial marker, later DLMO might reflect dysfunction of glial cell.

\section{DISCUSSION}

This review summarized the results of previous studies on the melatonergic system in child, adolescent, and young adult patients with mood disorders and participants with high risk (Table 1) [21-26,34-36]. Although there were not bunch of studies, acculmulating evidence showed that the abnormalities of melatonin system have been found in early phase of mood disorders. The abnormal patterns of melatonin systems were not consistent. However, these inconstient findings might reflect the charcteristics of subjects and differential effect of diagnostic subtype $[23,34]$. The influences of sex and psychosexual development should be noted on changes of melatonin secretion. In addition, characteristics such as diagnostic subtype and clinical features reflecting changes of adrenergic neurotransmission related to melatonin regulation should be considered. Current evidence implys that bipolar disorder is likely to be lower melatonin secretion or imparimed melatonin system 
compared to major depressive disorder [34]. However, there was few studies to conclude the differential effects of diagnostic subtype on melatonin system. Thus, more studies are needed to explore this relationship between diagnostic subtype and changes of melatonin system. Interestingly, one study revealed possibily differential effect of presence of psychotics symptoms on melatonin secretion, despite of statistical non-significance [23]. Considering that dopamine might decrease melatonin synthesis and secretion, these findings could be interpretable [37-39]. We can infer that clinical features associated with changes of dopaminergic neurotransmission as well as adrenergic neurotransmission have a substantial influence on changes of melatonin system in depression [37-40].

In addition, decrease in melatonin secretion were related to depressive symptom severity in depression with delayed phases and prognositic factors such as cognitive impariments and socio-occupational dysfunction' (Table 2) $[23-26,35,36]$. Melatonin generally acts as an antioxidant [41]. Under the condition of low melatonin secretion or higher melatonin suppression, oxidative damage could be increased [19]. The oxidative stress could lead to cognitive impairment and decline $[42,43]$. Given that, low melatonin syndomre might be associated with cognitive dysfunction and poor social-occupational function. Furtheremore, one study repored that late DLMO reflecting delayed phase of melatonin secretion was dysfunction of glial cell [35]. Glial cell might be important contributors to the regulation of sleep-wake cycle [44]. Glia-mediated neuroinflammation and glial ceel dysfunction could lead to the disturbance of sleep-wake cycle [44].

Therefore, proper correction on altered melatonin systems such as lower melatonin syndrome and delayed shifiting on melatonin secretionis warranted [19]. Early intervention for correction on abnormalities of melatonin system in child, adolescent, and young adult patients with mood disorder should be considered. Most studies support that melatonin replacement could be crucial intervention to improve low melatonin syndrome and advance melatonin rhythm in mood disorders [45]. However, because patients in child and adolescence are on the growth period, determental influence of melatonin replacement on development of brain and neuroendo-

Table 2. Associated factors with changes of melatonin system inchild, adolescent, and young adults with mood disorders

\begin{tabular}{|c|c|c|c|}
\hline Author (year) & Period & Diagnosis & Findings \\
\hline Shafii et al. [23], 1996 & Child to adolescent & MDD & $\begin{array}{l}\text { Serum melatonin level } \\
\text {-Sex: NS }\end{array}$ \\
\hline Naismith et al. [24], 2012 & Adolescent and young adults & MDD & $\begin{array}{l}\text { Salivary melatonin AUC } \\
\text { - BDI: NS } \\
\text { - HDRS: NS } \\
\text { - RAVLT encoding: (+) }\end{array}$ \\
\hline Carpenter et al. [25], 2017 & Young adults & Affective disorders & $\begin{array}{l}\text { Salivary melatonin level } \\
\text {-HDRS: NS } \\
\text { - SOFAS: }(+)\end{array}$ \\
\hline Carpenter et al. [36], 2017 & Young adults & Affective disorders & $\begin{array}{l}\text { Delayed phase cluster: using sleep-wake } \\
\text { cycle } \\
\text {-HDRS: NS } \\
\text { - Sex: NS } \\
\text { - SOFAS: NS }\end{array}$ \\
\hline Robillard et al. [35], 2017 & Young adults & MDD & $\begin{array}{l}\text { Salivary DLMO } \\
-\mathrm{MI} / \mathrm{CrPCr}:(-) \\
\text { - HDRS: NS }\end{array}$ \\
\hline Robillard et al. [26], 2018 & Young adults & MDD & $\begin{array}{l}\text { Delayed phase cluster: DLMO and CBT } \\
- \text { HDRS } \uparrow \\
- \text { YMRS } \uparrow\end{array}$ \\
\hline
\end{tabular}

MDD, major depressive disorder; NS, non-significance; AUC, area under the curve; BDI, Beck Depression Inventory; HDRS, Hamilton Depression Rating Scale; RAVLT, Rey Auditory Verbal Learning Test; (+), positive correlation or association; SOFAS, Social and Occupational Functioning Scale; DLMO, dim light melatonin onset; MI, myo-inositol; CrPCr, creatinine/phosphocreatine; (-), negative correlation or association; CBT, core body temperature; $\uparrow$, increase; YMRS, Young Mania Rating Scale. 
crine system should be carefully considered. Several researchers insist that melatonin replacement in child and adolescent period could be effective and safe on disturbed sleep-wake cycles [46-48]. Especially, melatonin supplements have already been used in pediatric patients in attention-deficit hyperactivity disorder, autism, and in pediatric patients with neurological disorders [46-48]. These studies have reported several side effects of melatonin supplements in pediatric patients such as diarrhea, dizziness, headache, hypothermia, increased enuresis, and morning drowsiness [46-48]. However, no serious side effects have been reported yet [46-48]. Thus, melatonin replacement might be potential intervention for altered melatonin secretion in child, adolescent, and young adults with mood disorders. However, research is needed to confirm whether the early use of melatonergic agents in people with growth period has determental influence on development of brain and neuroendocrine system.

\section{CONCLUSION}

This review summarized the results of previous studies on the melatonergic system in child, adolescent, and young adult patients with mood disorders and high risk groups. Given that the previous studies, the abnormalities of melatonin system have been found in early phase of mood disorders. Thought the abnormal patterns of melatonin systems were not consistent, these inconstient findings might reflect the charcteristics of subjects in early phase of mood disordersand differential effect of diagnostic subtype. In addition, the abnormalities of melatonin system were associated with clinical features, such as depressive symptomatology, cognitive impairment, and poor prognosis. Potentially, the abnormalities of melatonin systems might be related to the pathogehesis of mood disorders. Early evaluation and intervention of melatonin system are warranted in child, adolescent, and young adult patients with mood disorders and high risk groups.

\section{CONFLICTS OF INTEREST}

The authors have nothing to disclose.

\section{ACKNOWLEDGEMENTS}

This work was supported by the National Research Foundationof Korea (NRF) grant funded by the Korea government(MSIT) (No. NRF-2017R1C1B5074937).

\section{ORCID}

\author{
Jung Hyun Lee \\ https://orcid.org/0000-0002-0496-9826 \\ Eunsoo Moon \\ https://orcid.org/0000-0002-8863-3413
}

\section{REFERENCES}

1. Mishima K, Tozawa T, Satoh K, Matsumoto Y, Hishikawa Y, Okawa M. Melatonin secretion rhythm disorders in patients with senile dementia of Alzheimer's type with disturbed sleep-waking. Biol Psychiatry 1999;45:417-21.

2. Savaskan E, Olivieri G, Brydon L, Jockers R, Kräuchi K, Wirz-Justice A, et al. Cerebrovascular melatonin MT1receptor alterations in patients with Alzheimer's disease. Neurosci Lett 2001;308:9-12.

3. Bastos MAV Jr, Oliveira Bastos PRH, Portella RB, Soares LFG, Conde RB, Rodrigues PMF Jr, et al. Pineal gland and schizophrenia: a systematic review and meta-analysis. Psychoneuroendocrinology 2019;104:100-14.

4. Sahbaz C, Özer OF, Kurtulmus A, K@¥rp@ ¥nar I, Sahin F, Guloksuz S. Evidence for an association of serum melatonin concentrations with recognition and circadian preferences in patients with schizophrenia. Metab Brain Dis 2019;34:865-74.

5. Bersani G, Mameli M, Garavini A, Pancheri P, Nordio M. Reduction of night/day difference in melatonin blood levels as a possible disease-related index in schizophrenia. Neuro Endocrinol Lett 2003;24:181-4.

6. Srinivasan V, Smits M, Spence W, Lowe AD, Kayumov L, Pandi-Perumal SR, et al. Melatonin in mood disorders. World J Biol Psychiatry 2006;7:138-51.

7. Lee JH, Moon E. Changes of the melatonergic system in bipolar disorder: a literature review. Mood Emot 2019;17:418.

8. Lam RW, Berkowitz AL, Berga SL, Clark CM, Kripke DF, Gillin JC. Melatonin suppression in bipolar and unipolar mood disorders. Psychiatry Res 1990;33:129-34.

9. Kennedy SH, Kutcher SP, Ralevski E, Brown GM. Nocturnal melatonin and 24-hour 6-sulphatoxymelatonin levels in various phases of bipolar affective disorder. Psychiatry Res 1996;63:219-22.

10. Hallam KT, Begg DP, Olver JS, Norman TR. Abnormal 
dose-response melatonin suppression by light in bipolar type I patients compared with healthy adult subjects. Acta Neuropsychiatr 2009;21:246-55.

11. Nathan PJ, Burrows GD, Norman TR. Subsensitive melatonin suppression by dim white light: possible biological marker of panic disorder. Int J Neuropsychopharmacol 1998; 1:115-20.

12. Fountoulakis KN, Karamouzis M, Iacovides A, Nimatoudis J, Diakogiannis J, Kaprinis G, et al. Morning and evening plasma melatonin and dexamethasone suppression test in patients with nonseasonal major depressive disorder from northern Greece (latitude 40-41.5 degrees). Neuropsychobiology 2001;44:113-7.

13. Rabe-Jabłońska J, Szymańska A. Diurnal profile of melatonin secretion in the acute phase of major depression and in remission. Med Sci Monit 2001;7:946-52.

14. Carvalho LA, Gorenstein C, Moreno RA, Markus RP. Melatonin levels in drug-free patients with major depression from the southern hemisphere. Psychoneuroendocrinology 2006;31:761-8

15. Crasson M, Kjiri S, Colin A, Kjiri K, L'Hermite-Baleriaux M, Ansseau M, et al. Serum melatonin and urinary 6-sulfatoxymelatonin in major depression. Psychoneuroendocrinology 2004;29:1-12.

16. DeFilippis MS, Wagner KD. Bipolar depression in children and adolescents. CNS Spectr 2013;18:209-13.

17. Baweja R, Mayes SD, Hameed U, Waxmonsky JG. Disruptive mood dysregulation disorder: current insights. Neuropsychiatr Dis Treat 2016;12:2115-24.

18. Sundberg I, Ramklint M, Stridsberg M, Papadopoulos FC, Ekselius L, Cunningham JL. Salivary melatonin in relation to depressive symptom severity in young adults. PLoS One 2016; 11:e0152814.

19. Hardeland R. Neurobiology, pathophysiology, and treatment of melatonin deficiency and dysfunction. ScientificWorldJournal 2012;2012:640389.

20. Kennaway DJ, Stamp GE, Goble FC. Development of melatonin production in infants and the impact of prematurity. J Clin Endocrinol Metab 1992;75:367-9.

21. Cavallo A, Holt KG, Hejazi MS, Richards GE, Meyer WJ 3rd. Melatonin circadian rhythm in childhood depression. J Am Acad Child Adolesc Psychiatry 1987;26:395-9.

22. Waterman GS, Ryan ND, Perel JM, Dahl RE, Birmaher B, Williamson DE, et al. Nocturnal urinary excretion of 6-hydroxymelatonin sulfate in prepubertal major depressive disorder. Biol Psychiatry 1992;31:582-90.

23. Shafii M, MacMillan DR, Key MP, Derrick AM, Kaufman N, Nahinsky ID. Nocturnal serum melatonin profile in major depression in children and adolescents. Arch Gen Psychiatry 1996;53:1009-13.

24. Naismith SL, Hermens DF, Ip TK, Bolitho S, Scott E, Rogers NL, et al. Circadian profiles in young people during the early stages of affective disorder. Transl Psychiatry 2012;2:e123.

25. Carpenter JS, Robillard R, Hermens DF, Naismith SL, Gor- don C, Scott EM, et al. Sleep-wake profiles and circadian rhythms of core temperature and melatonin in young people with affective disorders. J Psychiatr Res 2017;94:131-8.

26. Robillard R, Carpenter JS, Rogers NL, Fares S, Grierson $\mathrm{AB}$, Hermens DF, et al. Circadian rhythms and psychiatric profiles in young adults with unipolar depressive disorders. Transl Psychiatry 2018;8:213.

27. Ghaziuddin N, Shamseddeen W, Bertram H, McInnis M, Wilcox HC, Mitchell PB, et al. Salivary melatonin onset in youth at familial risk for bipolar disorder. Psychiatry Res 2019;274:49-57.

28. Wetterberg L, Bergiannaki JD, Paparrigopoulos T, von Knorring L, Eberhard G, Bratlid T, et al. Normative melatonin excretion: a multinational study. Psychoneuroendocrinology 1999;24:209-26.

29. Gunn PJ, Middleton B, Davies SK, Revell VL, Skene DJ. Sex differences in the circadian profiles of melatonin and cortisol in plasma and urine matrices under constant routine conditions. Chronobiol Int 2016;33:39-50.

30. Cain SW, Dennison CF, Zeitzer JM, Guzik AM, Khalsa SB, Santhi N, et al. Sex differences in phase angle of entrainment and melatonin amplitude in humans. J Biol Rhythms 2010;25:288-96.

31. Luboshitzky R, Dharan M, Goldman D, Herer P, Hiss Y, Lavie P. Seasonal variation of gonadotropins and gonadal steroids receptors in the human pineal gland. Brain Res Bull 1997;44:665-70.

32. Ekmekcioglu C. Melatonin receptors in humans: biological role and clinical relevance. Biomed Pharmacother 2006;60:97-108.

33. Cardinali DP, Vacas MI, Keller Sarmiento MI, Etchegoyen GS, Pereyra EN, Chuluyan HE. Neuroendocrine integrative mechanisms in mammalian pineal gland: effects of steroid and adenohypophysial hormones on melatonin synthesis in vitro. J Steroid Biochem 1987;27:565-71.

34. Robillard R, Naismith SL, Rogers NL, Scott EM, Ip TK, Hermens DF, et al. Sleep-wake cycle and melatonin rhythms in adolescents and young adults with mood disorders: comparison of unipolar and bipolar phenotypes. Eur Psychiatry 2013;28:412-6.

35. Robillard R, Lagopoulos J, Hermens DF, Naismith SL, Rogers NL, White D, et al. Lower in vivo myo-inositol in the anterior cingulate cortex correlates with delayed melatonin rhythms in young persons with depression. Front Neurosci 2017;11:336.

36. Carpenter JS, Abelmann AC, Hatton SN, Robillard R, Hermens DF, Bennett MR, et al. Pineal volume and evening melatonin in young people with affective disorders. Brain Imaging Behav 2017;11:1741-50.

37. Nguyen-Legros J, Chanut E, Versaux-Botteri C, Simon A, Trouvin JH. Dopamine inhibits melatonin synthesis in photoreceptor cells through a D2-like receptor subtype in the rat retina: biochemical and histochemical evidence. J Neurochem 1996;67:2514-20.

38. Zisapel N. Melatonin-dopamine interactions: from basic 
neurochemistry to a clinical setting. Cell Mol Neurobiol 2001;21:605-16.

39. González S, Moreno-Delgado D, Moreno E, Pérez-Capote K, Franco R, Mallol J, et al. Circadian-related heteromerization of adrenergic and dopamine DCp receptors modulates melatonin synthesis and release in the pineal gland. PLoS Biol 2012;10:e1001347.

40. Ceinos RM, Chansard M, Revel F, Calgari C, Míguez JM, Simonneaux V. Analysis of adrenergic regulation of melatonin synthesis in Siberian hamster pineal emphasizes the role of HIOMT. Neurosignals 2004;13:308-17.

41. Beyer CE, Steketee JD, Saphier D. Antioxidant properties of melatonin--an emerging mystery. Biochem Pharmacol 1998;56:1265-72.

42. Mulero J, Zafrilla P, Martinez-Cacha A. Oxidative stress, frailty and cognitive decline. J Nutr Health Aging 2011;15: 756-60.

43. Revel F, Gilbert T, Roche S, Drai J, Blond E, Ecochard R, et al. Influence of oxidative stress biomarkers on cognitive decline. J Alzheimers Dis 2015;45:553-60.

44. Garofalo S, Picard K, Limatola C, Nadjar A, Pascual O, Tremblay MÈ. Role of glia in the regulation of sleep in health and disease. Compr Physiol 2020;10:687-712.

45. Cardinali DP, Srinivasan V, Brzezinski A, Brown GM. Melatonin and its analogs in insomnia and depression. J Pineal Res 2012;52:365-75.

46. Sánchez-Barceló EJ, Mediavilla MD, Reiter RJ. Clinical uses of melatonin in pediatrics. Int J Pediatr 2011;2011: 892624.

47. Bruni O, Alonso-Alconada D, Besag F, Biran V, Braam W, Cortese $\mathrm{S}$, et al. Current role of melatonin in pediatric neurology: clinical recommendations. Eur J Paediatr Neurol 2015;19:122-33.

48. Esposito S, Laino D, D’Alonzo R, Mencarelli A, Di Genova $\mathrm{L}$, Fattorusso A, et al. Pediatric sleep disturbances and treatment with melatonin. J Transl Med 2019;17:77. 